КАЛЬЧЕНКО А.С., аспірант кафедри інформаційних систем та мереж (Навчально-науковий інститут холоду, кріотехнологій та екоенергетики ім. В.С. Мартиновського Одеської національної академії харчових технологій)

\title{
Інтелектуальна система управління якістю послуг в мережах наступного покоління
}

У роботі представлено метод управління якістю послуг в мережах наступного покоління, який дозволяє ефективно відстежувати і підтримувати ступінь задоволеності користувачів послугами на необхідному рівні. Метод заснований на використанні апаратів нечіткої логіки та нейронних мереж.

Ключові слова: управління якістю послуг, мережі наступного покоління, нечітка логіка, нейронні мережі, вимоги користувачів.

\begin{abstract}
Постанова проблеми
Стрімкий розвиток $\mathrm{i}$ поширення інфокомунікаційних технологій набуває сьогодні характер глобальної інформаційної революції. У абонентів з'явилася потреба в послугах зв'язку, які можна було б гнучко налаштовувати відповідно до їх вимог. Мережі наступного покоління (Next Generation Networks, NGN) являють собою єдину транспортну платформу, на базі якої об'єднуються різні види послуг. Застосування мереж наступного покоління дозволяє значно розширити спектр інтелектуальних послуг. I саме на сучасному етапі розвитку, коли на базі однісї мережі надаються усі види послуг, отримують особливе значення мультимедійні послуги.

Одним з основних аспектів, який повинен братися до уваги при проектуванні мереж NGN, є забезпечення відповідної якості обслуговування. 3 впровадженням мультисервісних мереж переважаючим стає підхід до завдання рівня обслуговування на підставі вимог самих абонентів до якості послуг.
\end{abstract}

\section{Аналіз останніх досліджень і публікацій \\ Роботи вітчизняних і зарубіжних вчених щодо управління якістю послуг в мережах наступного покоління свідчать про необхідність удосконалення системи управління послугами. Серед зарубіжних i вітчизняних авторів, які вирішували окремі завдання в цій галузі, можна відзначити наступних: Dogman A., Saatchi R., Al-Khayatt S., Jaber M., Combaz J., Strus L., Fernandez J., Golmohammadi A., Jahandideh B., Radhakrishnan K., Larijani Н., Гольдштейн Б.С., Гольдштейн О., Соколов М., Атцик О., Пінчук О., Ісаченко Ю., Лесін Л., Князєва Н., Стеклов В., Беркман Л., Кільчицький Є., Макаров В., Костік Б., Фергюсон П., Хастон Р., Стародуб Н., Паршенков Н., Кучерявий А., Росляков А., Ваняшин С., Самсонов М.,}

(C) А.С. Кальченко, 2015
Чечнева I., Бітнер В., Міхайлова Ц., Острох С., Єфремов О., Дудник та інші.

Виділення невирішених раніше частин загальної проблеми

Незважаючи на значну кількість робіт по управлінню якістю телекомунікаційних послуг, в них переважно приділяється увага технічним показникам якості послуг, в той час як на сьогоднішній день $є$ потреба в ефективних методах урахування думки користувача при управлінні якістю послуг.

Таким чином, актуальною $є$ розробка удосконаленої системи управління якістю послуг в мережах наступного покоління, в якій оцінка якості послуг включає в себе як об'єктивну оцінку мережевих характеристик, так i суб'єктивну експертну та користувацьку оцінку. Для цього найбільш доцільно використовувати методи штучного інтелекту, оскільки саме вони дозволяють максимально ефективно оцінити думку користувачів стосовно QoS (Quality of services).

Метою даної роботи $\epsilon$ вдосконалення системи управління якістю послуг в мережах наступного покоління для отримання можливості найбільш ефективного врахування вимог користувачів до якості послуг.

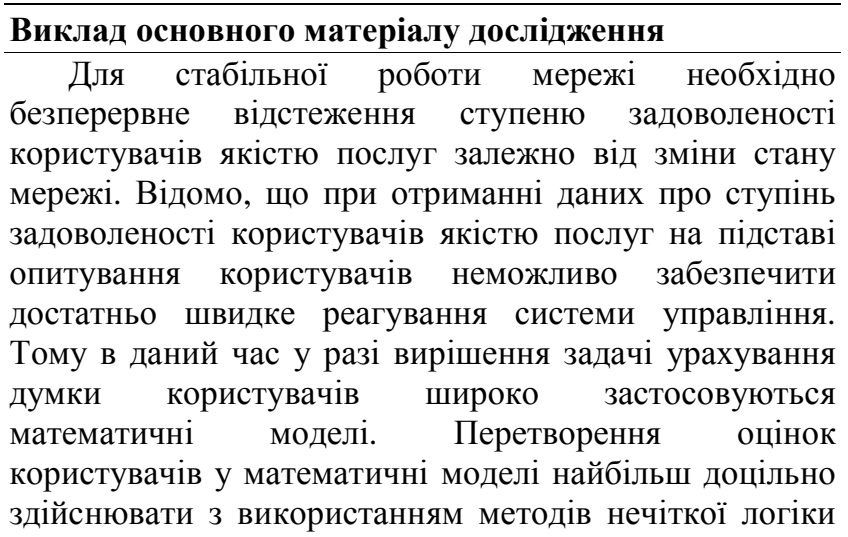


та нейронних мереж. Найважливішою перевагою нейронних мереж $\epsilon$ можливість їх навчання та адаптації. Нечітка логіка, яка служить основою для реалізації методів нечіткого управління, більш природно описує характер людського мислення і хід його міркувань, ніж традиційні формально-логічні методи.

У даній роботі запропоновано систему оцінки якості послуг, в якій в результаті порівняння користувальницьких оцінок якості послуг 3 еталонними показниками якості виконуються необхідні коригуючі дії.

На підставі рекомендацій МСЕ-Т Е.802 [1] i необхідності врахування вимог користувачів в роботі пропонується реалізація процесу забезпечення якості послуг, у схему якого введено блок оцінки ступеня задоволеності користувачів якістю послуг, реалізований з використанням методів нечіткої логіки та нейронних мереж.

Дамо коротку характеристику блокам системи:

1. Еталонні показники якості. Визначаються постачальником послуг і фахівцями-експертами.

2. Аналіз. Блок здійснює свої функції, коли проводяться дослідження якості надаваних послуг i виконується порівняння досягнутих показників якості 3 встановленими еталонними показниками та інформацією, переданої каналами зворотного зв'язку від ієрархічної нечіткої системи. У разі необхідності виробляє відповідні керуючі дії.

3. Процес надання послуги. Цей блок представляє собою процес, розроблений постачальником послуг для надання послуг 3 таким рівнем якості, який визначено еталонними показниками якості.

4. Результат. Це якість послуг, фактично надана користувачам постачальником послуг, що є результатом процесу забезпечення якості.

5. Іерархічна нейронечітка система (IHC). На підставі об'єктивних вимірів характеристик роботи мережі та даних, отриманих в результаті опитування користувачів, визначається ступінь задоволеності користувачів якістю послуг.

Більш детально систему описано в роботі [2].

На сьогоднішній день все більше поширення отримують мультимедійні послуги, що включають в себе одночасну передачу даних, відео та звуку. Для оцінки якості мультимедійних послуг згідно рекомендації МСЕ-Т Е.802 застосовна модель чотирьох ринків, що виділяє наступні компоненти: створення контенту, управління послугою, мережу доставки i клієнтське обладнання. При цьому враховується поділ між транспортним рівнем і рівнем послуг.

Враховуючи те, що показник по кожному 3 компонентів, у свою чергу, залежить від множини критеріїв, в даній роботі реалізацію моделі чотирьох ринків запропоновано представляти як ієрархічну систему. Це дозволяє отримати комплексну всебічну оцінку якості послуг, що враховує всі аспекти створення та надання послуги. В розробленій ієрархічній системі вихід однієї бази знань подається на вхід іншої бази знань. На першому рівні ієрархії визначаються значення, що досягаються кожним 3 компонентів якості послуги $\left(Y_{1}, Y_{2}, \ldots, Y_{i}, \ldots, Y_{p}\right)$. На другому рівні ієрархії залежно від значень, досягнутих по кожному 3 компонентів $Y_{i}$, визначається підсумковий показник $Z$ - ступінь задоволеності користувача послугою. Модель являє функціональне відображення виду:

$X=\left\{X_{1}\left(x_{11}, w_{11} ; x_{12}, w_{12} ; \ldots ; x_{1 n}, w_{1 n}\right)\right.$,

$X_{2}\left(x_{21}, w_{21} ; x_{22}, w_{22} ; \ldots ; x_{2 m}, w_{2 m}\right), \ldots$,

$\left.X_{p}\left(x_{p 1}, w_{p 1} ; x_{p 2}, w_{p 2} ; \ldots ; x_{p q(i)}, w_{p q(i)}\right)\right\} \rightarrow$

$Y=\left\{Y_{1}, w_{1} ; Y_{2}, w_{2} ; \ldots ; Y_{i}, w_{i} ; \ldots ; Y_{p}, w_{p}\right\} \rightarrow Z$.

Тут $X$ - вектор впливаючих факторів, $x_{i j}$ - показники, що впливають на компонент якості $Y_{i}$,

$w_{i}$ - значимість, «вага» компонентів $Y_{i}(i=\overline{1, p})$,

$w_{i j}$ - значимість, «вага» показників $x_{i j}(i=\overline{1, p}$, $j=\overline{1, q(i)})$,

$p$ - кількість компонентів якості,

$q(i)$ - кількість показників, що впливають на компонент якості $Y_{i}$.

«Вагу» $w_{i j}$ показників запропоновано виражати в бальній системі на основі експертних оцінок.

У блоці аналізу визначається, чи відповідає ступінь задоволеності користувачів послугою рівню, визначеному еталонними показниками якості [2]. У разі невідповідності система визначає причину порівнює фактичні показники якості (QoS, досягнуте оператором) 3 еталонними значеннями (QoS, що пропонується оператором). При цьому спочатку аналізуються компоненти якості $Y_{i}(i=\overline{1, p})$, потім, у разі виявленні відхилень, показники якості $x_{i j}(i=\overline{1, p}$, $j=\overline{1, q(i)})$ компонентів, значення яких не відповідають необхідному рівню Корекцію показників якості пропонується проводити 3 урахуванням необхідних витрат. Вважаючи існуючі вартісні обмеження на коррекцію показників якості, вводяться наступні показники: величина витрат $C_{i j}(i=\overline{1, p}, j=\overline{1, q(i)})$, необхідних для корекції показника якості $x_{i j}$, і загальна

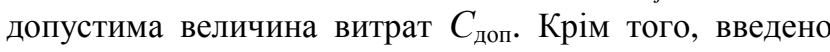
відносну величину $\gamma_{i j}$, що характеризує приріст показника якості $x_{i j}$ на одиницю вартості

$\gamma_{i j}=w_{i j} \frac{x_{i j}(k+1)-x_{i j}(k)}{C_{i j} * x_{i j}(k)}$. 
Тут $k$ - номер етапу.

Відзначимо, що процес корекції показників якості представляється послідовністю етапів, на кожному 3 яких необхідно для всіх показників якості $x_{i j}$, які потребують корекції, розрахувати значення $\gamma_{i j}$ i вибрати максимальне.

Далі проводиться моделювання з використанням ієрархічної нейронечіткої системи, в результаті якого ми отримуємо імовірну реакцію користувачів на зміну рівня якості послуг. Таким чином будуть відкориговані ті показники, зміна яких призведе до максимально позитивного результату в рамках допустимих витрат. Важливо, що процес аналізу рівня QoS та корекції показників відбувається в режимі реального часу, без проведення додаткових опитувань. Це зменшує витрати та дозволяє негайно реагувати на несприятливі поєднання значень показників якості і попереджати ситуації, коли користувач незадоволений якістю отриманих послуг. За рахунок використання методів нечіткої логіки та нейронних мереж реалізована можливість не тільки моделювання ступеня задоволеності користувачів, але й запам'ятовування найкращого стану мережі.

Для реалізації експертної системи виконано моделювання 3 використанням адаптивної мережі нечіткого виводу ANFIS (Adaptive-Network-Based Fuzzy Inference System) системи Matlab. На базі Matlab було розроблено GUI-додаток, який реалізує роботу системи.

На рис. 1 показано структуру верхнього рівня ієрархії адаптивної мережі нейронечіткої виведення.

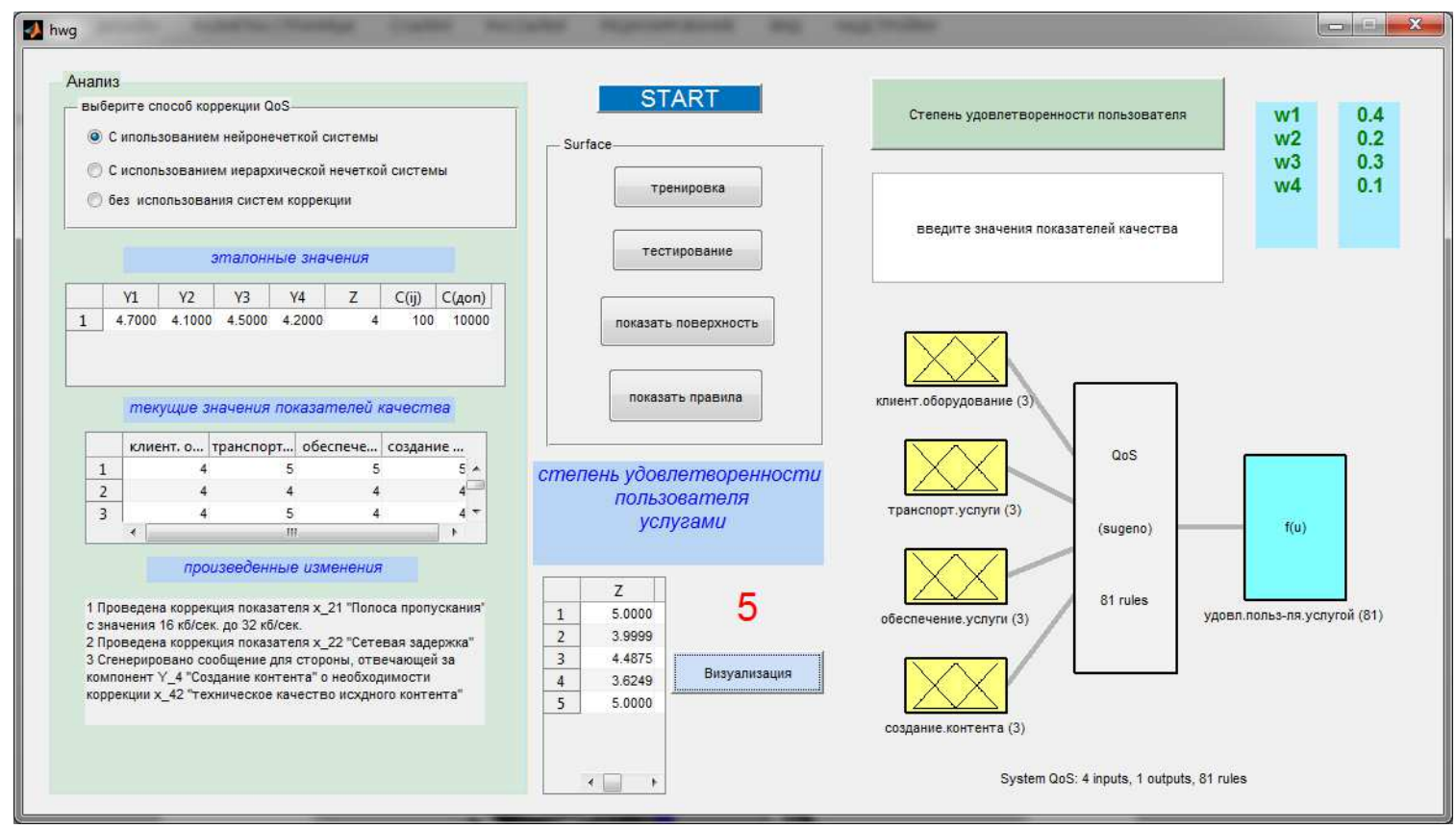

Рис. 1. Структура верхнього рівня ієрархії адаптивної мережі нейронечіткого виводу

На базі користувальницьких оцінок (розмір вибірки - 300 користувачів вікової групи $15, \ldots, 75$ років) була сформована навчальна вибірка, на підставі якої була згенерована адаптивна мережа нейронечіткого виводу для визначення ступеня задоволеності користувачів послугами.

На рис. 2 зображено результати процесу навчання. Використовувався гібридний метод навчання. Кількість епох - 20.

Нейро-нечітку мережу можна розглядати як одну 3 різновидів систем нечіткого логічного висновку типу Сугено. При цьому функції приналежності синтезованих систем налаштовані так, щоб мінімізувати відхилення між результатами нечіткого моделювання та експериментальними даними. ANFIS реалізує систему нечіткого виводу Сугено у вигляді п’ятислойної нейронної мережі прямого поширення сигналу. На рис. 3 зображено структуру нейронечіткої мережі.

Розроблений додаток відображає еталонні значення показників якості, а також поточні значення показників. В разі виявлення відхилення ступіню задоволеності користувача від еталонного значення, в блоці аналізу відбувається перевірка компонентів та показників якості, i, в разі виявлення відхилення, виробляються необхідні коригуючі дії. На рис. 4 зображено приклад використання системи для перегляду поверхні нечіткого виводу системи MATLAB при аналізі результатів роботи системи для змінних «Транспорт послуги» та «Клієнтське обладнання» 3 використанням нечіткої (рис. 4 а) та нейронечіткої мережі (рис. 4 б). 


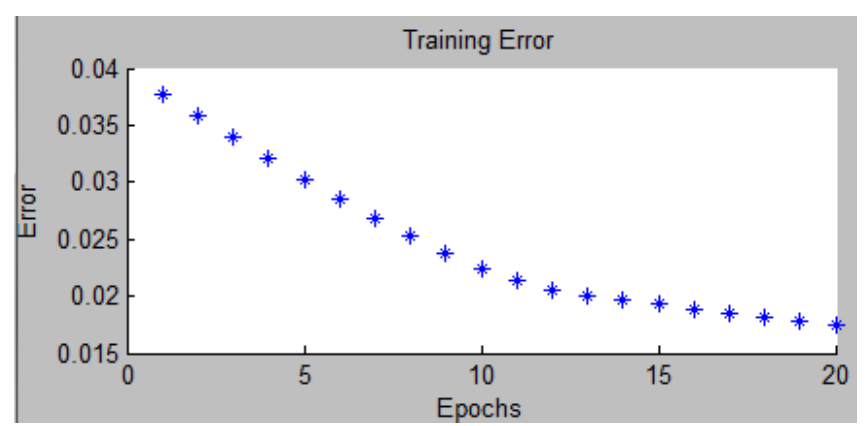

a)

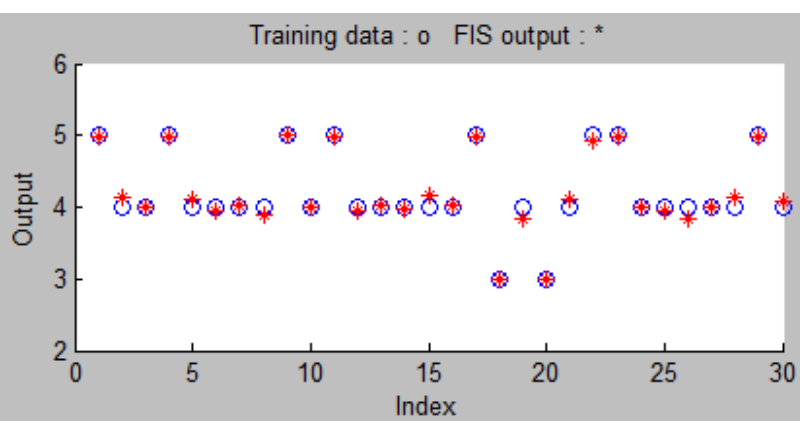

б)

Рис. 2. Результати навчання нейронечіткої мережі визначення ступіню задоволеності користувача послугами: а) величина помилки; б) порівняння даних навчальної та тестуючої вибірок

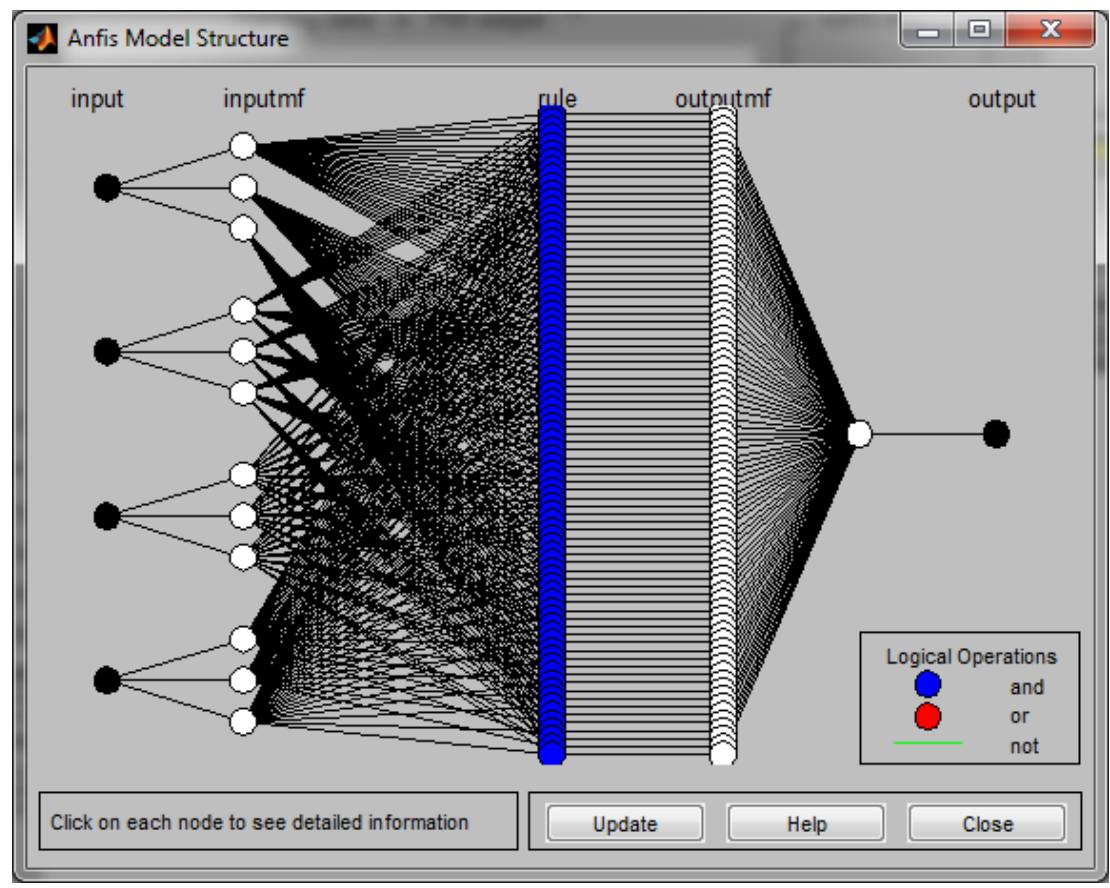

Рис. 3. Структура нейронечіткої мережі визначення ступіню задоволеності користувача якістю послуг

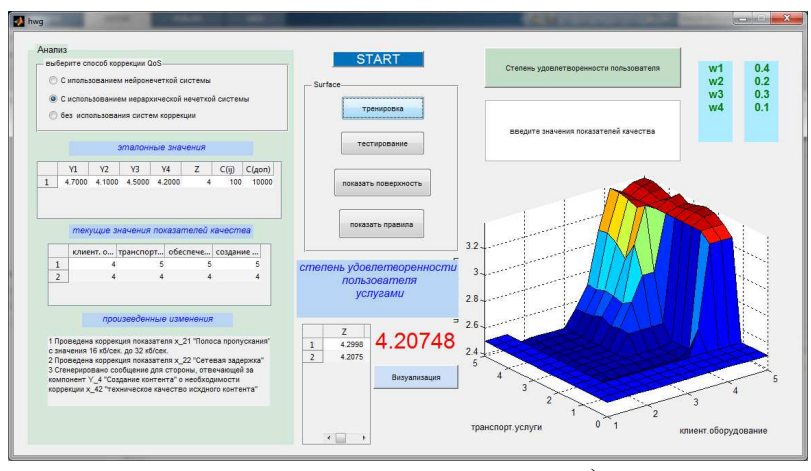

a)

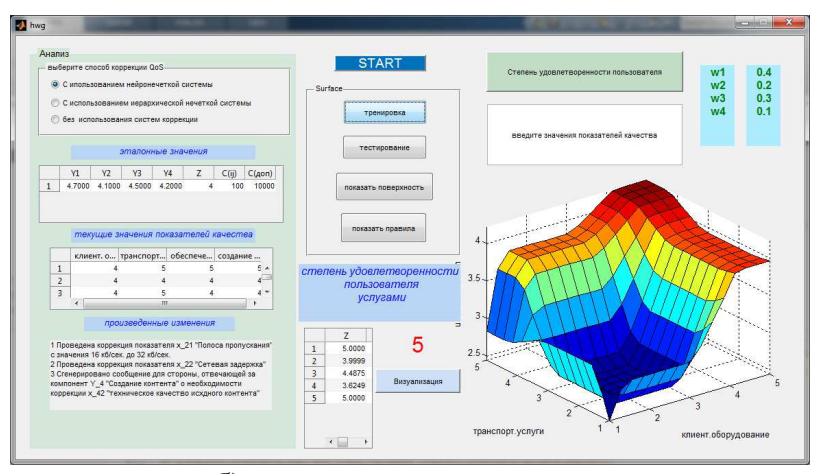

б)

Рис. 4. Приклад використання програми для перегляду поверхні нечіткого виводу системи MATLAB при аналізі результатів роботи системи для змінних «Забезпечення послуги» та «Клієнтське обладнання» 
У результаті моделювання визначено, що найбільший вплив на ступінь задоволеності користувачів послугою надають компоненти «Забезпечення послуги» та «Кліснтське обладнання». Чим важливіше показник якості послуги для користувачів, тим менше варіацій у значенні даного показника якості наданої послуги вони готові прийняти. Крім того, система дозволяє визначити, які критерії по кожному з компонентів мають найбільший вплив на результат - ступінь задоволеності користувача якістю послуг.

На основі аналізу отриманих результатів роботи системи визначено, що більш точні результати забезпечує використання нейронечіткої ієрархічної мережі (рис. 5). Це поянюється здатністю нейронних мереж до навчання, завдяки чому система здатна самостійно уточнювати функції приналежності на основі отриманих даних.

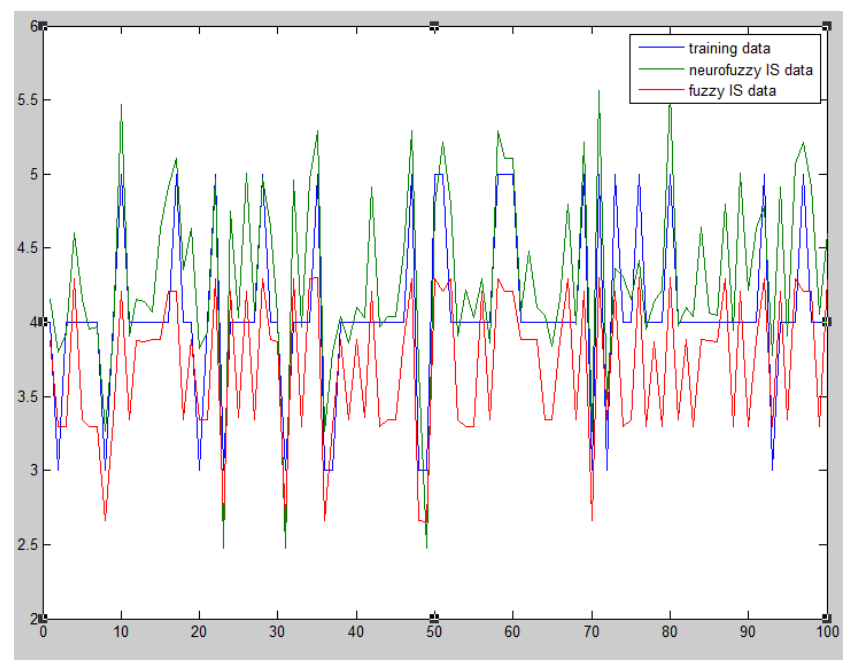

Рис. 5. Порівняння результатів роботи системи визначення ступіню задоволеності користувача 3 використанням нечіткої та нейронечіткої мереж

\begin{tabular}{l}
\hline Висновки \\
\hline Запропонована система управління якістю послуг в \\
мережах наступного покоління дозволяє ефективно \\
враховувати думку користувачів. На відміну від \\
існуючих систем подібного роду, в яких управління \\
якістю здійснюється в основному на базі технічних \\
характеристик, запропонована система дає можливість \\
врахувати як технічні аспекти роботи мережі, так і \\
користувальницькі оцінки якості наданих послуг. \\
Використання ієрархічної нейронечіткої системи \\
дозволяє отримати комплексну всебічну оцінку якості \\
послуг. Крім того, система дозволяє реалізувати \\
додаткові можливості - провести моделювання \\
користувальницького відгуку на зміни значень \\
показників якості без проведення додаткових \\
опитувань, а також запам'ятовувати оптимальний стан
\end{tabular}

мережі. На відміну від існуючих систем управління якістю, застосування запропонованого методу дає можливість знайти саме ті показники якості, поліпшення яких дозволить досягти максимального ефекту в рамках допустимих витрат.

Таким чином, запропонований підхід дозволяє визначити найбільш значущі для користувачів показники якості послуг і підтримувати їх стан на такому рівні, при якому користувачі задоволені якістю отриманих послуг.

\section{Література}

1. ITU-T Recommendation E.802 - Framework and methodologies for the determination and application of QoS parameters, Geneva, 2007.

2. Князева Н.А., Кальченко А.С. Управление качеством услуг в сетях следующего поколения с использованием методов нечеткой логики // Холодильна техніка та технологія, 51 (4), ОНАХТ, 2015 - C.102-107.

Кальченко А. С. Интеллектуальная система управления качеством услуг в сетях следующего поколения. В работе представлен метод управления качеством услуг в сетях следующего поколения, который позволяет эффективно отслеживать и поддерживать степень удовлетворенности пользователей услугами на необходимом уровне. Метод основан на использовании аппаратов нечиткой логики и нейронных сетей.

Ключевые слова: управление качеством услуг, сети следующего поколения, нечеткая логика, нейронные сети, требования пользователей

Kalchenko A.S. Intelligent service quality control system in next generation networks. The paper presents a method for service quality management in next generation networks that allows effectively tracking the degree of user's satisfaction with QoS and maintaining it at the required level. The proposed system provides an opportunity to take into account both technical network aspects and custom service quality evaluation. This becomes possible due to the introduction of quality control system of the hierarchical neuro-fuzzy system into service, which allows getting comprehensive service quality evaluation. The proposed system is based on the fuzzy logic and neural networks methods, because these methods allow evaluating user opinion most effectively. The way of GUI development on Matlab to model intelligent service quality control system using Adaptive Networkbased Fuzzy Inference System (ANFIS) is presented in this study. The developed system allows identifying the most important for QoS user criteria and maintain their condition at required level at which user is satisfied with the quality of received services. 
Key words: service quality management, next generation networks, fuzzy logic, neural networks, user requirements.

Рецензент д.т.н., професор Князєва Н.О. (ОНАХТ)

Поступила 11.11.20152.

Кальченко Анастасия Сергеевна, аспирант кафедры Информационных систем и сетей (Учебно-научный институт холода, криотехнологий и экоэнергетики им. В.С. Мартыновского Одесской национальной академии пищевых технологий)

Kalchenko Anastasia S., post-graduate student of the Information systems and networks department (Odessa National Academy of Food Technologies, V.S.Martynovsky Educational-Scientific Institute of Refrigeration, Cryotechnologies, and Ecoenergy) 